Research Article

\title{
Design, Control, Modeling, and Simulation of Mechanical Ventilator for Respiratory Support
}

\author{
Anh Son Tran, ${ }^{1,2}$ Ha Quang Thinh Ngo ${ }^{10},{ }^{1,2}$ Van Keo Dong, ${ }^{3}$ and Anh Huy Vo ${ }^{1,2}$ \\ ${ }^{1}$ Faculty of Mechanical Engineering, Ho Chi Minh City University of Technology (HCMUT), 268 Ly Thuong Kiet, District 10, \\ Ho Chi Minh 700000, Vietnam \\ ${ }^{2}$ Vietnam National University Ho Chi Minh City, Linh Trung Ward, Thu Duc District, Ho Chi Minh 700000, Vietnam \\ ${ }^{3}$ Faculty of Mechanical, Electrical, Electronic and Automotive Engineering, Nguyen Tat Thanh University, \\ Ho Chi Minh 700000, Vietnam
}

Correspondence should be addressed to Ha Quang Thinh Ngo; nhqthinh@hcmut.edu.vn

Received 24 July 2021; Revised 8 September 2021; Accepted 27 September 2021; Published 24 November 2021

Academic Editor: Carlos Llopis-Albert

Copyright $(2021$ Anh Son Tran et al. This is an open access article distributed under the Creative Commons Attribution License, which permits unrestricted use, distribution, and reproduction in any medium, provided the original work is properly cited.

In the early stage of the 21st century, humankind is facing high medical risks. To the best of our knowledge, there is currently no efficient way to stop chains of infections, and hence citizens suffer significantly increasing numbers of diseases. The most important factor in this scenario is the lack of necessary equipment to cure disease and maintain our living. Once breath cannot be guaranteed, humans find themselves in a dangerous state. This study aimed to design, control, model, and simulate mechanical ventilator that is open-source structure, lightweight, and portable, which is proper for patients to cure themselves at home. In the scope of this research, the hardware platform for the mechanical design, implementation of control rules, and some trials of both simulations and experiments are presented as our methodology. The proposed design of ventilator newly features the bioinspired mechanism, finger-like actuator, and flow rate-based control. Firstly, the approximate evaluation of the lung model is presented with some physiological characteristics. Owing to this investigation, the control scheme was established to adapt to the biological body. Moreover, it is essential for the model to be integrated to determine the appropriate performance of the closed-loop system. Derived from these theoretical computations, the innovative concept of mechanical design was demonstrated using the open-source approach, and the real-world model was constructed. In order to estimate the driving torque, the hardware modeling was conducted using mathematical expressions. To validate the proposed approach, the overall system was evaluated using Matlab/Simulink, and experiments with the proposed platform were conducted in two situations: $20 \mathrm{lpm}$ as a reference flow rate for 4 seconds and $45 \mathrm{lpm}$ for 2.5 seconds, corresponding to normal breath and urgent breath. From the results of this study, it can be clearly observed that the system's performance ensures that accurate airflow is provided, although the desired airflow fluctuates. Based on the test scenario in hardware, the RMS (root-mean-square) values of tracking errors in airflow for both cases were 1.542 and 1.767. The proposed design could deal with changes in airflow, and this machine could play a role as a proper, feasible, and robust solution to support human living.

\section{Introduction}

Artificial ventilation support is a life-saving method that is utilized to provide enough air. Most patients that require this could not breathe adequately on their own. This technique is also used to deal with respiratory failures as well as during and after major surgical operations. One of the most popular respiratory supports is positive pressure mechanical ventilation [1], which is employed in various modalities [2]. Recently, several technologies for ventilators have been developed to individually adjust the system parameters to match patients' requirements [3-6]. In those works, the key factor is to synchronize the human breathing rate with the frequency of breaths provided by the machinery system. It is absolutely true that any asynchrony between human and machine could cause 
severe distress and fatigue. Additionally, the excessive use of sedatives or prolongation of mechanical ventilation could occur during medical treatment. To encourage and support the patient's spontaneous breathing, many research works have been completed to indicate respiratory patterns that emulate or track a patient's own breathing pattern. For adaptive support ventilation (ASV), the control scheme plays an important role in automatically modifying deep breaths and the rate of respiration [7-9]. The purposes of control are to optimize the minimum rate of breathing and mimic the patient's breathing frequency in a natural way. In reverse, in neurally adjusted ventilatory assistance (NAVA), the trigger from the patient's own neural ventilatory signal drives the ventilating machine. The activated signal is identified by electrodes mounted on a nasogastric tube located at the lower esophagus $[10,11]$. In the last category, proportional assisted ventilation (PAV) supplies proportional pressure to the patient's own breathing effort during respiration. Basically, it is a weaning technique and cannot be utilized during the period of treatment [12-14].

In the last few months, there has been an increased demand for ventilators during the treatment process of COVID-19 (coronavirus disease 2019) patients [15]. In fact, the situation for humankind at this time has become very challenging. Even well-equipped hospitals have had to expend great efforts to meet the increase in the number of sick persons, such as sharing the same air supply between two patients [16], meaning that they could not satisfy all requirements at the same time. To deal with the worldwide trouble of ventilator shortage, developers have innovated to release low-cost, open-source ventilators $[17,18]$ for numerous patients. Basically, these developments are able to provide instantaneous responses in hospital or healthcare service. It is agreed that this approach might be potentially one of the best solutions for poor nations or emergency cases [19].

In fact, a mechanical ventilator is a device that supports humans to breathe in order to maintain their blood oxygenation. Breathing regularly starts with inspiratory activity when air enters the lung and ends with an exhalation of breath, when air is expired. The inspiration is prompted by differences in pressure naturally exerted by the diaphragm and the chest motion as well as by a machine-driven mechanism in the human airway that launches a flow of air. Expiring is passive and motivated by the elastic force of the tissues in the lung.

Despite the changes to noninvasive respiratory support, mechanical ventilation remains an essential tool for the medical care of critically ill patients. A variety of advanced techniques for medical devices with available modes and data fusion present potential solutions. Since various manufacturers utilize different nomenclature to depict relative modes of ventilation, communication among users of different machines has turned into a challenge. The working modes of mechanical ventilation are often categorized into the acts of breathing. Breaths could be started by a timing mechanism in spite of a person's inspiratory efforts. Alternatively, breaths might be prompted by the patient's inspiration, which is named as synchronization or patienttriggered ventilation.

\section{Motivations}

In general, there are clearly typical classifications of ventilation machines. Firstly, adaptive support ventilation [20, $21]$ or automatic compensation ventilation $[9,22]$ is one of the best examples in terms of patient-ventilator synchrony. The goal of this type of machine is to support the resistive work of breathing via the artificial airway. The control scheme is usually a form of pressure control, and the system modeled by the mathematical expression indicates the airway pressure from the inspiratory flow. This native breath is initiated with inspiration, which is triggered and cycled by the patient. A nurse or doctor should input the size and choose the proper airway. Then, the ventilation machine utilizes a look-up table to identify the airway resistance. In this case, the controller is intelligent enough to drive the whole system according to the installed mathematical model. This requires complex computations with a short response from the patient's inspiration. In these articles, the reasonable mechanism to avoid the failsafe mistake, the understandable control scheme to deal with the diversity of patients, and the ability to collect enough data are some achievable lessons.

In the second category, neurally adjusted ventilatory assistance $[23,24]$ is actually a servo targeting circuit that is similar to the first type of machine. However, it requires more complicated requirements for implementation. In the field of patient-ventilator synchrony [25], this machine assists both the resistive and elastic work of breathing in proportion to the patient's respiratory efforts. Although the severe acute exacerbations are out of this scope, the specific controlled trials and the status of patients in advance are beneficial for our study. Normally, the design controller must evaluate the airway pressure to be proportional according to the signal obtained from diaphragmatic activity. The user inserts the ratio value between voltage and pressure so that the controller manipulates the airway pressure. Besides, the third classification, called proportional assisted ventilation [26, 27], is also a servo targeting circuit, although it uses a more complex model than the two previous types. In the same method, this ventilator [28] provides both the resistive and elastic work of the breath related to the patient's respiratory effort. It receives different feedback signals in terms of patient-ventilator synchrony. Additionally, the working mechanism is to control pressure based on the equation of motion for the respiratory system. To start the operating mode, the user must put in the desired values for elastance and resistance to be supported. From these analyses, the correct setting of ventilating mode and patient-oriented design are rewarded.

In recent times, the concept of open-source hardware $[29,30]$ has gathered pace in our community, especially for mechanical ventilators $[31,32]$. Aiming at the treatment and prevention of COVID-19, modern microprocessor-based electronic devices $[33,34]$ have been embedded such that a complex control scheme, advanced functions, and powerful 
resources can be implemented. In [35], the researchers studied a microcontroller-driven mechanical ventilator using Ambu Bag which is pressed by the arm mechanism. The trajectory of mechanical components is planned by camshaft (CAM) generation. The output results present the timevarying characteristic of tidal volume. In the same method, but with a different mechanism, the authors in [29] developed a low-cost, open-source ventilator that was catalyzed by the global shortage of mechanical ventilator for COVID-19 patients. The driving motor, which is controlled by a Raspberry $\mathrm{Pi}$, provides a maximum pressure of up to $70 \mathrm{~cm} \mathrm{H}_{2} \mathrm{O}$. Additionally, although the design is simple but efficient, the experimental device for ventilation satisfies the desired volume and pressure in respect to clinical requirements [36]. For future steps, developers are discussing the reliability of the mechanisms and software, mass production with appropriate standards, and regulatory approval or exemption. With the aim of portability, the investigators in [37] introduced an easy-to-use and mobile version of the Ambu Bag-based compression machine. This system is manipulated by Arduino and offers various breathing modes with varying tidal volumes. The rate for breathing is 5 to 40 breaths/minute, and the maximum ratio between inhalation and exhalation is $1: 4$. The repeatability and ability to precisely exceed personal capabilities in this design were proved in experiments. Although the original design consisting of two paddles is actuated by an electric motor [38], there are still several efforts to develop pressure-controlled ventilation. It is noted that the usage of electromechanical actuators to press Ambu Bag is an excellent solution. Whether supplies of compressed air are available or not, the tidal volume could increase linearly [39].

The field of open-source mechanical ventilators has experienced a steep rise of contributions during the global pandemic. Although some countries have suffered a third or fourth wave of COVID-19, many predictions have been released that the number of ventilated patients is dramatically increasing, meaning that they will exceed the total supply of current ventilators in hospital or healthcare centers. Industrial developers, researchers, governments, and startups are motivated to enter the worldwide race to establish cheap, easy-tomanufacture mechanical ventilators. There is a diversity of these research works as clear design patterns are lacking, and the machines do not satisfy the minimum functional specifications or present hardly any innovation.

In this paper, a biomimetic study of a noninvasive mechanical ventilator has been proposed in the emergent situation. The purpose of our work is to design, control, model, and simulate mechanical ventilator with an opensource hardware, high mobility, and less heaviness for home-based treatment. The technical features of proposed ventilator consist of the bioinspired mechanism, finger-like actuator, and flow rate-based control. In this methodology, the physiological model of the lung is estimated to mimic the particular characteristics of the human body. Additionally, this implementation of theoretical modeling could create the closed-loop control scheme. Later, the conceptual mechanism of an overall ventilator is represented in detail together with a $3 \mathrm{D}$ model. In order to identify the driving torque from actuators, the dynamic performance of the mechanical prototype is analyzed. From these achievements, it is seen clearly that our approach is a feasible, effective, and capable solution in the emergent scenario. In particular, it achieves the requirements of being of low-cost, available, and easy to maintain in poor nations. The rest of this paper is constructed as follows. Section 3 demonstrates the mathematical expressions of the lung model according to the physical evaluations. From the academic estimation, the illustration of the control loop is presented in the first part of Section 4. Furthermore, the internal structure of the conceptual scheme and mechanical computations are depicted in detail in the second part of Section 4, while many achievements in both numerical simulation and practical implementation are made in Section 5. Finally, several conclusions and future works are presented in Section 6.

\section{Fundamental Model of Breathing}

In the initial stage, it is necessary to present the model of breathing mechanics to offer a basic picture of how the ventilation system works. This model is simplified and illustrates the relations among system variables. It is particularly focused on the pressure needed to drive gas into the airway and inflate the lung. Therefore, the physical model of breathing mechanics $[22,26]$ that is mostly used is a rigid flow conducting tube connected to an elastic compartment, as shown in Figure 1. This is a simplification of the above model from the viewpoint of pressure, volume, and flow. It is noted that the interface is not taken into account in this model because it is often insignificant. The lung and flow from the mouth are considered as the volume and airway, respectively. In this case, there are some notations due to the motion of the respiratory system. The transrespiratory pressure is characterized from the input air to volume while the transairway pressure and transthoracic pressure are symbolized as its components. When entering our body, the air meets the reaction from muscles, named as resistance. In addition, the ratio between the change of volume and the variation of pressure in the lung is referred to as compliance.

The mathematical model that relates pressure, volume, and flow during ventilation is named as the equation of motion [21] for the respiratory system:

$$
P_{\text {muscle }}+P_{\text {ventilator }}=\left(E \times V_{\text {ins }}\right)+(R \times F l) .
$$

Similarly, this equation could be rewritten in terms of compliance as follows:

$$
P_{\text {muscle }}+P_{\text {ventilator }}=\left(\frac{V_{\text {ins }}}{C}\right)+(R \times F l) .
$$

Pressure, volume, and flow are time-dependent variables that are calculated in relation to their end-expiratory values. Under normal conditions, these values are a muscle pressure of 0 , ventilator pressure of 0 , volume of the functional residual capacity, and a flow of 0 . During mechanical ventilation, these values are a muscle pressure of 0 , ventilator pressure of PEEP, volume of the end-expiratory volume, and a flow of 0 . Elastance and resistance are constants, where 


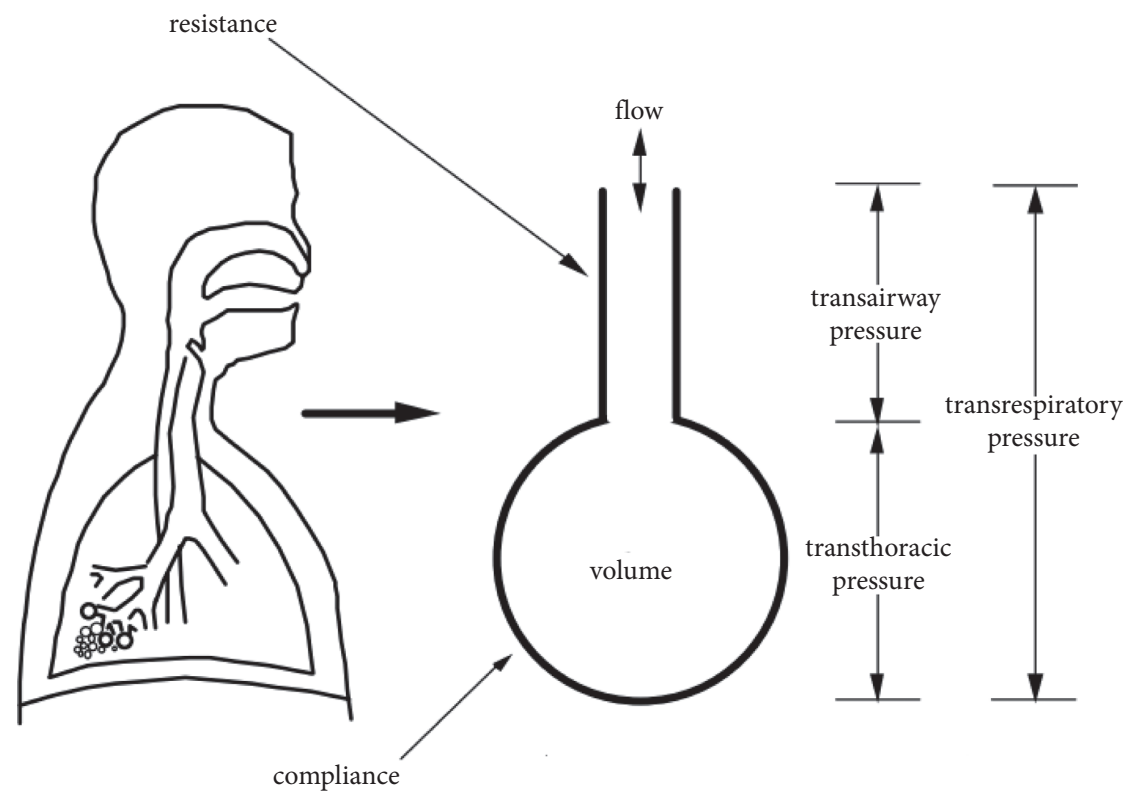

FIGURE 1: Modeling simulation of the ventilatory system.

$$
\begin{aligned}
& E=\frac{\Delta \text { transthoracic pressure }}{\Delta \text { volume }}, \\
& R=\frac{\Delta \text { the airway pressure }}{\Delta \text { flow }} \\
& C=\frac{\Delta \text { volume }}{\Delta \text { transthoracic pressure }} .
\end{aligned}
$$

Inspiration is aided when the airway pressure increases above the baseline, as shown by the ventilator's monitor. The pressure driving inspiration is named the transrespiratory system pressure $P_{\text {trans }}$. It is measured by the pressure at the airway opening $P_{\text {opening }}$ such as the mouth, endotracheal channel, or tracheostomy tube and is subtracted from the pressure at the body level $P_{\text {body }}$, or $P_{\text {trans }}=P_{\text {opening }}-P_{\text {body }}$. Transrespiratory system friction is the force that propels inspiration. The transairway pressure, defined as the airway opening pressure minus the lung pressure, and transthoracic pressure are two components of the transrespiratory system pressure, determined as the lung pressure minus body surface pressure. The term transpulmonary pressure $P_{\text {transpulmonary }}$ may be used to describe the difference between the airway opening pressure $P_{\text {opening }}$ and pleural pressure $P_{\text {pleural }}$, or $P_{\text {transpulmonary }}=P_{\text {opening }}-P_{\text {pleural }}$.

The theoretical (unmeasurable) transrespiratory system pressure exerted by the ventilatory muscles to expand the thoracic cage and lungs is referred to as the muscle pressure. The pressure caused by the ventilator in the transrespiratory system is known as ventilator pressure. Air enters the lungs as a result of the combination of muscle and ventilator pressures. Additionally, elastance in combination with resistance contributes to the load that the muscles and ventilator must operate against. It is noted that load has the units of pressure, so the left side of the equation equals the right side. As a result, the equation of motion might also be expressed as

$$
P_{\text {muscle }}+P_{\text {ventilator }}=E_{\text {load }}+R_{\text {load }} \text {. }
$$

The elastic load, which refers to the pressure necessary to deliver, is computed by the elastance times tidal volume, while the resistive load is the pressure required to deliver the surge estimated by resistance times flow. Multicompartment models are useful in some debates $[40,41]$. In this paper, some notations use electrical engineering symbols to ease the drawing of these models. A resistor is used to represent airway resistance in electronics, while a capacitor is used to represent conformity. The ventilator can be interpreted as a constant voltage source (pressure controller) or as a constant current source (a flow controller). A multicompartment model using electrical components is presented in Figure 2.

The resistance and conformity of the right and left lungs are modeled as independent sequence relations $[18,42]$. The two lungs, on the other hand, are bound in tandem. The endotracheal tube is in series with the patient circuit resistance. The breathing system and the patient circuit enforcement are in sync. The conformity of the chest wall corresponds to that of the lungs. By inserting a switch that alternately links the patient and patient circuit to the positive pole of the ventilator (inspiration) or to the ground, the role of the exhalation manifold can be shown (the negative pole is used for expiration).

\section{Proposed System Model}

4.1. Design of Pressure Volume Control Scheme. In the initial stage, it is necessary to mention the model of breathing mechanics. Regarding the electrical representation, when a circuit only contains a resistor and a capacitor ( $\mathrm{RC}$ circuit), this means that the sum of the voltage drops, as the resistance $(R)$ and the capacitance $(C)$, is equal to the applied voltage $E(t)$ according to Kirchhoff's second law [43, 44]. 


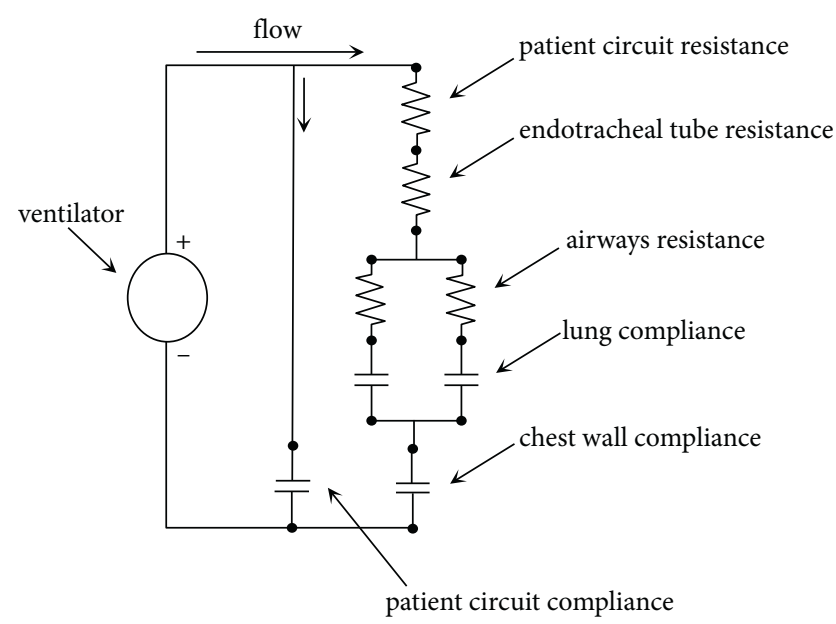

(a)

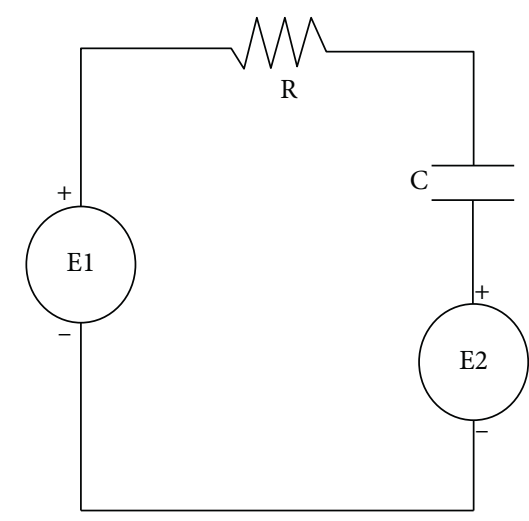

(b)

Figure 2: Modeling of multicompartment respiratory system and ventilator: (a) general model and (b) simplified model.

Additionally, the voltage drop across a capacitor of capacitance $C$ is $q(t) / C$, where $q$ is the charge on the capacitor. Therefore, for the indicated series circuit, and according to Kirchhoff's second law, we have (7) as follows:

$$
R+\frac{q}{C}=E_{1}(t)-E_{2}(t)
$$

However, the current $i$ and charge $q$ are related by $i=\mathrm{d} q / \mathrm{d} t$. Thus, the equation becomes the linear differential (6):

$$
R \frac{\mathrm{d} q}{\mathrm{~d} t}+\frac{q}{C}=E_{1}(t)-E_{2}(t)
$$

Replacing the electrical parameters of the circuit (CR) in (6) by the ventilatory variables, we find that when applying an inlet pressure to the system (ventilator outlet pressure), less muscle pressure is generated at the time. If the inspiration caused by the pressure supplied by the mechanical ventilator occurs, the volume will vary according to the firstorder linear differential (7), which establishes that the total applied pressure is the sum of the pressure differences due to the compliance of the system and the airway resistance.

$$
R \frac{\mathrm{d} V_{\text {ins }}}{\mathrm{d} t}+\frac{V_{\text {ins }}}{C}=P_{1}(t)-P_{2}(t) .
$$

Equivalent to the model of the respiratory system, the analysis of Kirchhoff law is employed such that the voltage input is similar to the output voltage, for which there is a voltage drop in $(R)$ and $(C)$. By using (8), the inspiratory volume is determined. Furthermore, (9) is generated to allow the modeling of the transfer function:

$$
\begin{aligned}
& \frac{\mathrm{d} V_{\text {ins }}}{\mathrm{d} t}=\frac{\left(P_{\text {ventilator }}-P_{\text {muscle }}\right)}{R}-\frac{V_{\text {ins }},}{R C} \\
& \frac{\mathrm{d} V_{\text {ins }}}{\mathrm{d} t}=\frac{1}{R}\left[\left(P_{\text {ventilator }}-P_{\text {muscle }}\right)-\frac{V_{\text {ins }}}{C}\right] .
\end{aligned}
$$

In this part, we demonstrate the theoretical actions of pressure and muscles during forced inspiration by simulation. The operated one-pressure ventilator mode has been chosen. This work allows us to gain a deeper understanding of the relationship between muscle pressure and respiratory function. Moreover, this simulator is used for complex, interactive, and adaptive control to provide a systematic approach. Since any calculation of the dynamics of the respiratory system is accurate only if the muscles of respiration are inactive, the principle of muscle pressure is crucial. During assisted respiration, if the patient makes an inspiratory effort, they add an unmeasured volume of pressure to the pressure produced by the ventilator.

From here, the system models simulate the behavior of muscle pressure during inspiration, using a respiratory system model such as a unicompartmental model, as seen in Figure 1, estimating the supply of ventilator pressure $P_{\text {ventilator }}$, which is equivalent to voltage in the electrical circuit, and $P_{\text {muscle }}$, representing another voltage, which corresponds to the muscle pressure at the moment of inspiration. In the same way, $C$ is the compliance or lung compliance and $R$ is the airway resistance.

The purpose of our study is to design an automatic targeting scheme that permits the ventilating machine to regulate several set-points depending on a mathematical model. The data are derived from the physiological processes or feedback signals. In some cases, the artificial intelligence system or rule-based expert system could be embedded in order to adapt to the unexpected clinical aspects. Its drawbacks are that the setting procedure is not easily understood for users, expert knowledge is obligatory, and the programming level of the machine developer should be professional. Therefore, to cope with the feasible, robust, and proper requirements of this investigation, the proposed controller for our mechanical ventilator was implemented as shown in Figure 3. The left side was from the air source, which is mainly provided by Ambu Bag as the input signal. In our study, the airflow normally came from the bag of mechanical platform. The mechanical hardware includes actuators and other parts which are produced according to the theoretical computation. In this case, the inspiratory controller commands the driving mechanism such finger- 


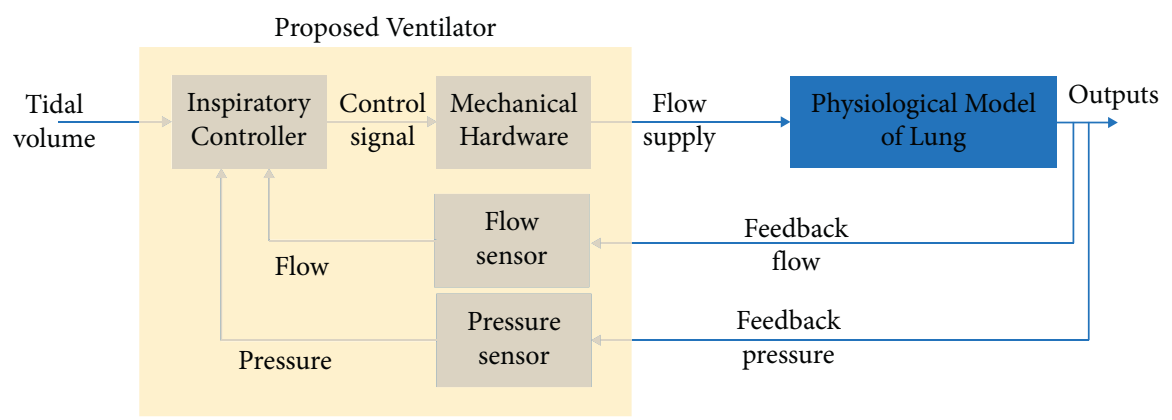

Figure 3: Proposed theoretical scheme for artificial ventilation.

like actuator, to supply the airflow based on the working mode. The purpose of control scheme is to manipulate the tracking error of flow rate to tend to zero. The lung model, which plays a role as the planning system, is integrated into this work from equation (10) and equation (11). Besides, sensing devices were directly linked with the other components to measure the feedback signals. The signal flow and feedback data, which is necessary to close the control scheme, are compared to the desired set-point in order to feed to proposed controller. The control circuit was designed so that inspiratory parameters related to PEEP could be automatically adjusted to satisfy the target tidal volume. Equation (10) gives some changes in resistance $(R)$, compliance $(C)$, and volume $\left(V_{\text {muscle }}\right)$ generated by patient effort $\left(P_{\text {muscle }}\right)$. The control rules were derived so that if $R$ increases or $C$ decreases, then the control signal would increase; if $V_{\text {muscle }}$ increases, then control signal would decrease [30, 40]. The proposed controller is written in the mathematical expression as below,

$$
\Delta P=\frac{\left(V_{\text {target }}-V_{\text {muscle }}\right)}{C\left(1-e^{-T_{i} / R C}\right)},
$$

where

$$
V_{\text {target }}=V_{\text {ventilator }}+V_{\text {muscle }} \text {. }
$$

From these equations, it could be noted that $\Delta P$ represents the difference between pressure of muscle or tissue and input pressure from ventilator. Due to the constraints of body human, target volume is totalized by input volume and the current volume that is absorbed by muscle during a period $T_{i}$. Additionally, the other parameters such as lung compliance and resistance in airway could be included in the design simulator. The purpose of these mathematical expressions is to predict the changes in volume and pressure according to the system parameters. Both of them closely relate to the flow rate of air which plays as a control variable in this research.

4.2. Hardware Design of Ventilator. The conceptual design of the mechanical ventilator in our research is shown in Figure 4. Due to the medical requirements for ventilators from the World Health Organization [45], this design must satisfy these following constraints:

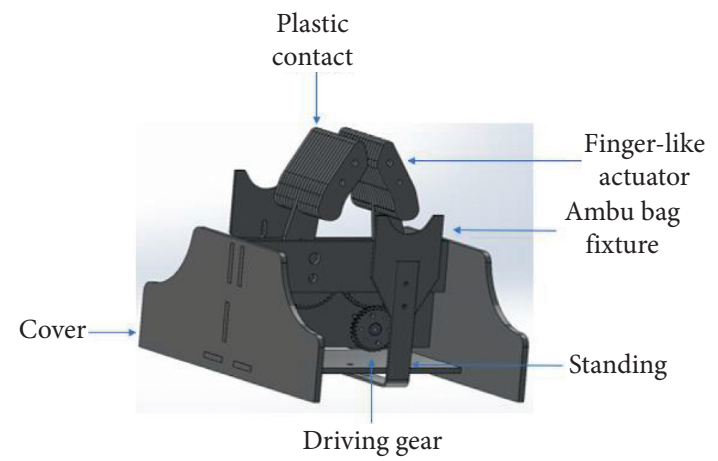

FIgURE 4: Three-dimensional design of the mechanical ventilator.

Peak pressure should be no more than $2 \mathrm{cmH}_{2} \mathrm{O}$ greater than plateau pressure

PEEP (positive end-expiratory pressure) must be maintained during expiration

For the ratio of inspiration phase/expiration phase, the ventilator must provide a ratio in the range of 1:1-1:3

The ventilator must provide a range of $10-30$ breaths per minute

Moreover, in order to be used in Vietnamese hospitals in the context of the global pandemic, some technical specifications are integrated into the proposed design:

Portability: The machine design should be easily carried by hand. It might be in use in households, healthcare centers, or hospitals. In some emergency cases, the proposed ventilator could be employed in outdoor situations.

Simplicity: The operator does not have to be an expert. A patient or relative could set the working mode and supervise the machine at their home.

Rapid maintenance and production: according to the special circumstances of social problems, medical personnel may be required to maintain or repair the device if the working conditions are not guaranteed. In addition, the manufacturer must produce a large number of machines as quickly as possible. The peripheral instruments should be available in the market frequently. 
To force the Ambu Bag, it is essential to mimic the natural gesture of the human hand. For the reason that nature is always the best and most efficient design, and because the hand can conform to the shape of the Ambu Bag, the interactive torque is evenly distributed so that the contact area and controllability are the greatest. However, the human hand has many joints and degrees of freedom (DOFs), and the action of both the hand and fingers to press the bag is complicated owing to the multi-DOF movement with many joints. Inspired by bioengineering design, two rigid fingers have curvatures like the bag and rotate in tandem around two symmetrical axes such that the maximum contact area is ensured with the least complexity. Figure 5 illustrates the mechanism of two fingers pressing the Ambu Bag. These two fingers are synchronized by the gear pattern at the bottom with a transmission ratio of $1: 1$ to certify the symmetrical movement. In addition, one of the fingers is driven by a pinion gear connected to the geared DC servo motor with an internal ratio of $1: 264$ and transmission ratio of $1: 1.56$ to amplify the driving torque.

Separately, the required holding power can be computed from the worst-case values as follows:

$$
\begin{aligned}
& \text { Maximum pressure at Ambu Bag: } \\
& P_{\text {airway,max }}=60 \mathrm{~cm} \mathrm{H}_{2} \mathrm{O} \text { (pop off relieve valve) } \\
& \text { Maximum respiration rate: } R R_{\max }=40 \mathrm{bpm} \\
& \text { Minimum inhale/exhale ratio of } 1: 4: \mathrm{IE}_{\text {ratio,min }}=4 \\
& \text { Maximum tidal volume: } V_{\max }=800 \mathrm{~cm}^{3}
\end{aligned}
$$

This means that, in the worst case, our machine needs to squeeze air at a pressure of $60 \mathrm{~cm} \mathrm{H}_{2} \mathrm{O}$ for 0.3 seconds.

$$
t_{\text {inhale }}(s)=\frac{60}{R R_{\max }} \times \frac{1}{1+I E_{\text {ratio,min }}} .
$$

The volume of air flow needed in the worst-case (peak) scenario is

$$
Q_{\text {airflow }}=\frac{V_{\max }}{t_{\text {inhale }}}=0.0027 \frac{\mathrm{m}^{3}}{\mathrm{~s}} .
$$

In the form of pressurized volume flow [30], the power output is

$$
\text { Power }_{\text {airflow }}=P_{\text {airflow, max }} Q_{\text {airflow }}=16 \mathrm{~W} .
$$

In contrast, some of the total amount of power in equation (14) to use to squeeze Ambu Bag is lost because of the bag deformation or friction. It is considered that $50 \%$ of the power is approximately converted to the pressurized volume flow. Taking this into account, the real power for the gripper is

$$
\text { Power }_{\text {gripper }}=2 \text { Power }_{\text {airflow }}=32 \mathrm{~W} \text {. }
$$

In equation (15), the actual power from the driving motor must be higher, and this value depends on the mechanical and electrical design. We assume that half of the motor power is lost by the mechanical and electrical inefficiencies (gears, thermal dissipation, etc.); then, it is computed as

$$
\text { Power }_{\text {motor }}=2 \text { Power }_{\text {gripper }}=64 \mathrm{~W} \text {. }
$$

To demonstrate our design, the pressing posture of the two-finger mechanism is shown in Figure 6. Three parameters must be measured: finger-bag contact area, finger lever arm length, and sweep angle. In this research, the physical dimensions of these items are as follows.

Finger-bag max contact area: $A_{\text {bag }}=90 \mathrm{~mm} \times 115 \mathrm{~mm}$

Finger lever arm length: $l_{\text {finger }}=12 \mathrm{~cm}$

Sweep angle: $\alpha_{\text {sweep }}=30^{\circ}$

Using the same $50 \%$ pressure transmission efficiency, the maximum force of the bag on one finger when fully squeezed is

$$
F_{\text {finger }}=2 A_{\text {bag }} P_{\text {airflow,max }}=81.199 \mathrm{~N} .
$$

The maximum torque on each finger is

$$
\tau_{\text {finger }}=F_{\text {finger }} l_{\text {finger }}=9.74 \mathrm{Nm} \text {. }
$$

Currently, the required power for a two-finger gripper using the sweep angular rate for 0.3 seconds is

$$
P_{\text {finger }}=2 \times \tau_{\text {finger }} \omega_{\text {finger }}=34.01 \mathrm{~W} \text {. }
$$

The total power for a single motor when additionally applying the same $50 \%$ efficiency of the motor and gearbox is

$$
P_{\text {motor }}=2 \times P_{\text {gripper }}=68.03 \mathrm{~W} \approx 70 \mathrm{~W} .
$$

Based on these computations, a one-gear DC servo motor is chosen as follows:

Power: $60 \mathrm{~W}$

Voltage: $24 \mathrm{~V}$

Reduced output speed: $33 \mathrm{rpm}$

Planet gearbox ratio: $1: 264$

Encoder: $3432 \mathrm{ppr}$

4.3. Simulator of Mechanical Ventilator. From the results of mechanical theory, the computed torque is expected that it sufficiently offers enough moment to control the actuators and driving mechanism. Owing to the adaptation for urgent breath, both the resolution of positioning encoder and the rotational speed of gearbox are selected carefully. Later, the outcome of the following simulations is to validate the effectiveness of proposed control scheme. Then, the experimental results are achieved to verify the practical ability of hardware platform. As lung compliance fluctuates with pulmonary disease, a ventilator must be able to offer a wide range of pressure in inspiration and sustain high pressure at the end process of exhalation. In practical terms, the open lung is achieved by utilizing adequate PEEP. For different reasons, such as a poorly conceived related study where moderate to high levels of PEEP were applied with the normal lung and resulted in significant impairment, many clinical treatments use adequate levels of end-expiratory pressure. 


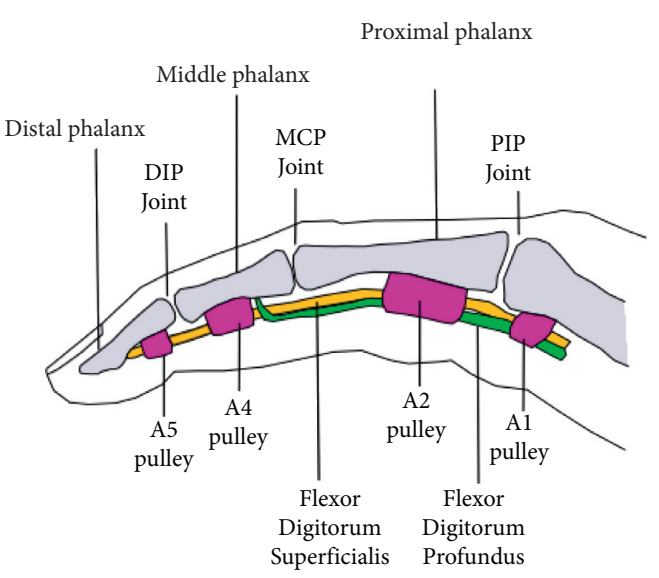

(a)

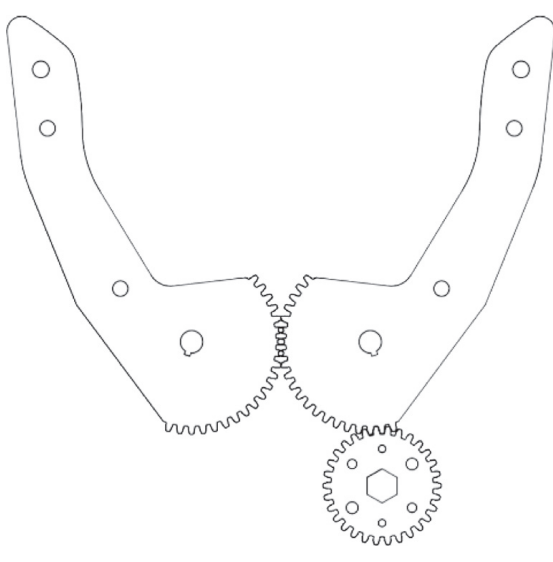

(b)

FIgURE 5: Mechanism of two fingers: (a) real structure of human finger and (b) bioinspired design of two fingers.

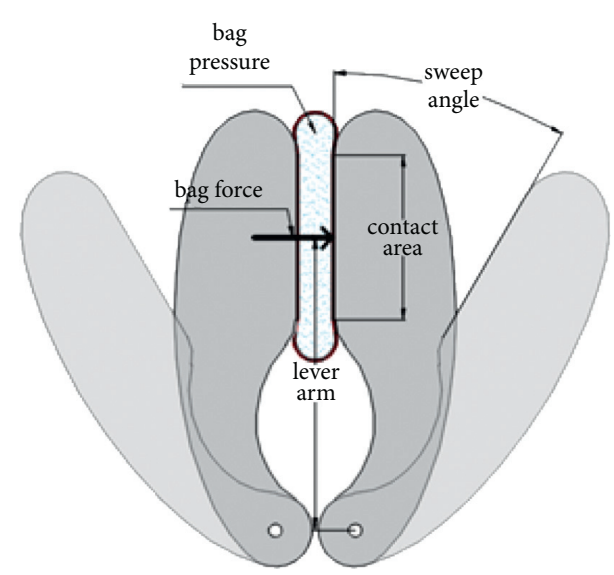

Figure 6: Illustration of the system parameters for two-finger mechanism.

The overall scheme of the ventilating process was simulated as shown in Figure 7, including the air exchange between the ventilator and human lung. Generally, the respiratory system of a person could be classified into the two zones, upper respiratory tract which is from noise to neck and lower respiratory tract which is the rest to lung. From the outside environment, the air from mechanical ventilator would flow to larynx that is mentioned as respiratory flow. Because of the absorbing process of oxygen in tissues, it could cause some differences between dead space flow and respiratory flow. In the lower tract, human's lung consists of alveoli which is denoted as alveolar flow. Besides, the lung model is also characterized by compliance and thoracic compliance. Commonly, the respiratory process involves two successive stages: inspiration and expiration. During inspiration, the respiratory muscles contract (intercostal muscles and diaphragm), which causes an increase in the volume of the rib cage and therefore a decrease in transpulmonary pressure. The lungs dilate, the pressure in the alveoli decreases, and the air enters the airways due to the pressure gradient generated. In expiration, the opposite process occurs to that of inspiration. The results of this work are expected to show that the proposed ventilator could basically provide enough air depending on the working mode. The tracking error of flow rate hopefully tends to zero when the air is provided via a mask.

\section{Results of Study}

To verify the effectiveness of our approach, the proposed model for a mechanical ventilator is simulated in this section. The initial physiological conditions [22] were chosen to verify the respiratory system of a patient whose lung injury is mild, as listed below:

$$
\begin{aligned}
& \text { Lung compliance }=0.1 \mathrm{~L} / \mathrm{cmH}_{2} \mathrm{O} \\
& \text { Thoracic compliance }=0.1 \mathrm{~L} / \mathrm{cmH}_{2} \mathrm{O} \\
& \text { Airway central resistance }=3 \mathrm{cmH}_{2} \mathrm{O} / \mathrm{L} / \mathrm{s} \\
& \text { Peripheral airway resistance }=0.5 \mathrm{cmH}_{2} \mathrm{O} / \mathrm{L} / \mathrm{s} \\
& \text { Airway tissue compliance }=0.005 \mathrm{~L} / \mathrm{cmH}_{2} \mathrm{O} \\
& \text { Breathing frequency }=15 \mathrm{bpm} \\
& \text { Peak pressure }=10 \mathrm{cmH}_{2} \mathrm{O} \\
& \mathrm{I}: E=1: 1
\end{aligned}
$$

The simulation results of the proposed approach are demonstrated from Figures 8 to Figure 12. The primary setting pressure in Figure 8 is square in shape, which is the desired performance, while the pressure of muscle response is estimated as shown in Figure 9. As an illustration of human performance, the adaptation of pressure in the lung is gradually decreased when it peaks at a maximum value, as shown in Figure 10. Generally, this implies that if the volume generated by the patient's muscle pressure is constant, the ventilator would increase the differential pressure even though the resistance or compliance of the patient increases. Consequently, Figures 11 and 12 represent the flows of the input airway and response of alveolar component. Since the lung is stiffer or flow is restricted by narrower airways, it would take more inspiratory pressure to reach the target tidal volume. It would be better if the respiratory controller were to receive more practical information from the patient 


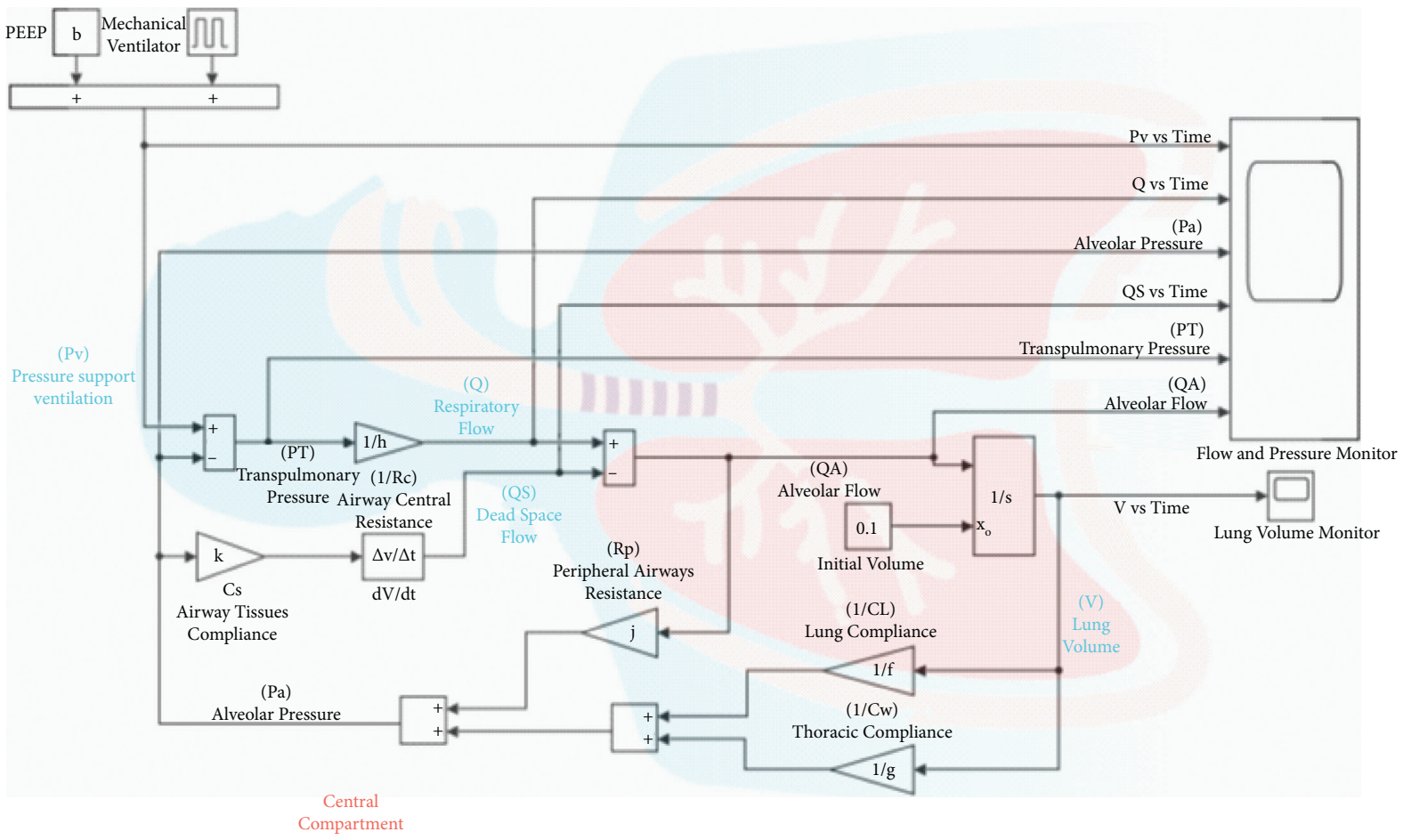

FIGURE 7: Overall simulator of ventilatory system.

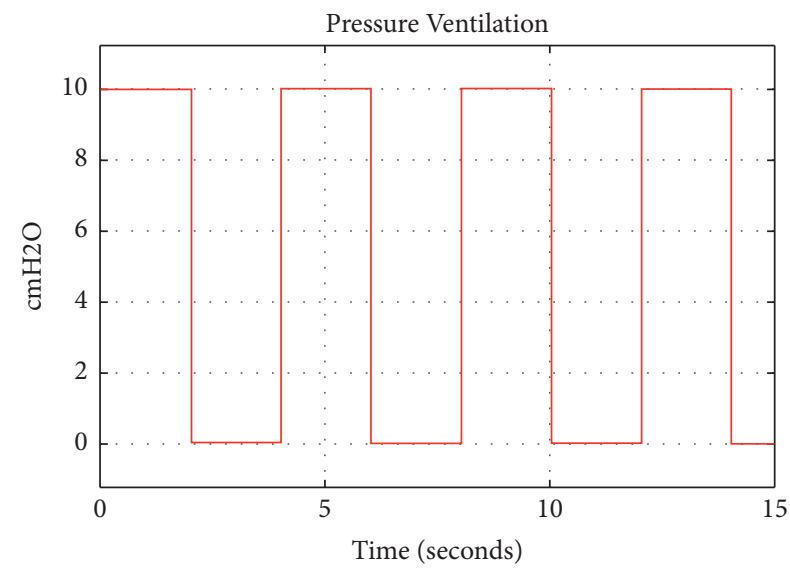

$\neg$ Pvvs Time

FIGURE 8: Simulation result of pressure support for mechanical ventilator.

via medical sensing devices. At that time, the ventilating machine could frequently follow the health status and effort of the patient.

Since the clinical evidence needed to be validated on practical platform, the real-world hardware of a noninvasive ventilator was used, as shown in Figure 13. To adapt to the lung of an adult, the proposed ventilator could achieve an average value of tidal volume of approximately $700 \mathrm{~mL}$. Generally, two fundamental symptoms of respiratory failure $[1,40]$ such as normal breath and urgent breath were chosen for verification in this platform. In the case of a normal test, the flow rate as a reference signal, provided in a period of 4 seconds, is $20 \mathrm{lpm}$. The other case depicts the respiratory

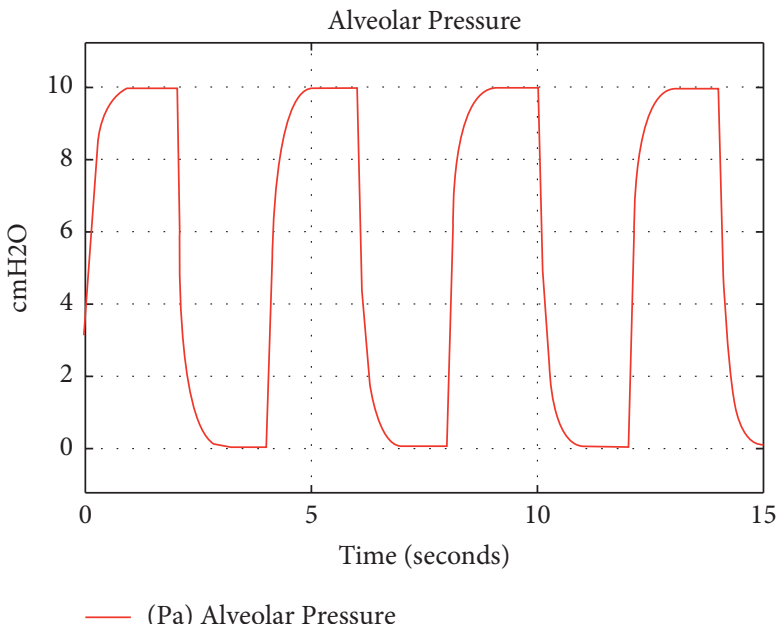

Figure 9: Simulation result of muscle pressure for mechanical ventilator.

failure that might occur at home suddenly. The urgent breath could be evaluated with a larger flow rate of $45 \mathrm{lpm}$ in a shorter time of 2.5 seconds. The overall system, which consists of a controller, power unit, user interface, mechanics, signal processing, and sensing devices, is shown in Figure 14. The user-oriented interface is mostly displayed by control panel while the push buttons specify the power status and emergency stop. In the control loop, STM32F407 CPU plays as the main microprocessor which is powerful in computation and signal processing. To avoid the reversed current and protect the main controller, DCS3T-28 servo driver is integrated to provide the sufficient DC current to 


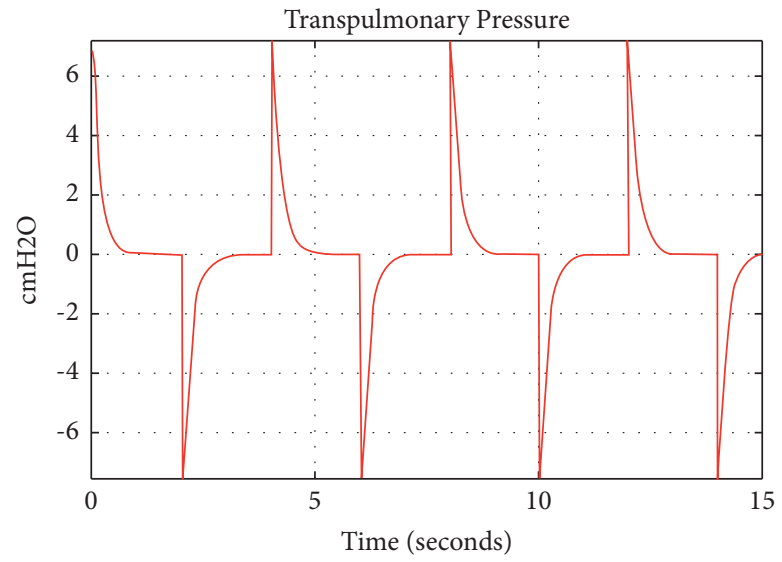

(PT) Transpulmonary Pressure

FIGURE 10: Simulation result of transpulmonary pressure for mechanical ventilator.

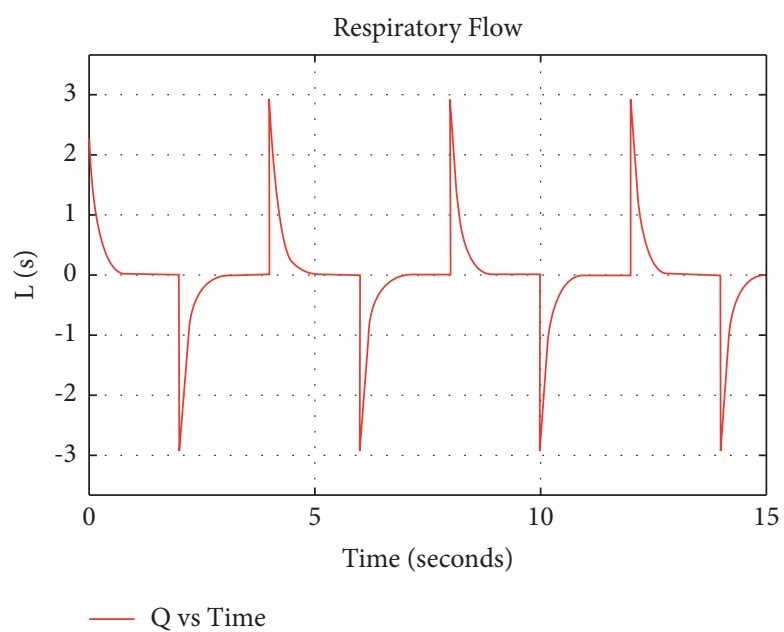

FIGURE 11: Simulation result of respiratory flow for mechanical ventilator.

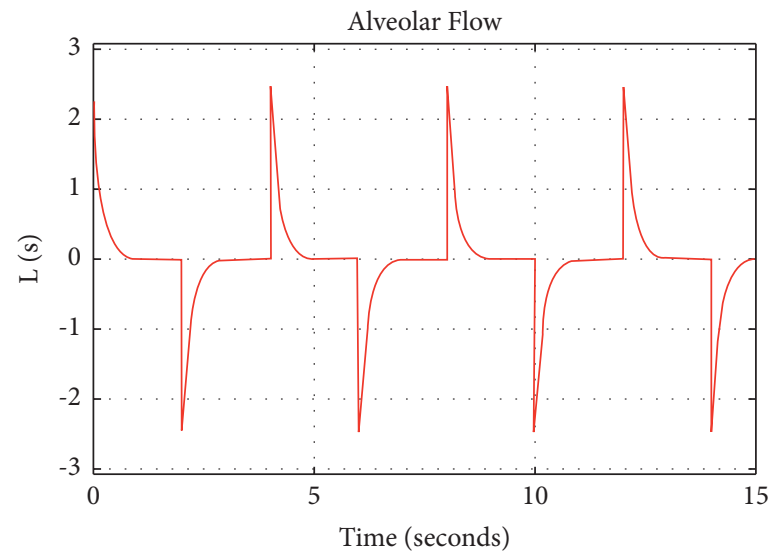

(QA) Alveolar Flow

FIgURE 12: Simulation result of alveolar flow for mechanical ventilator. 


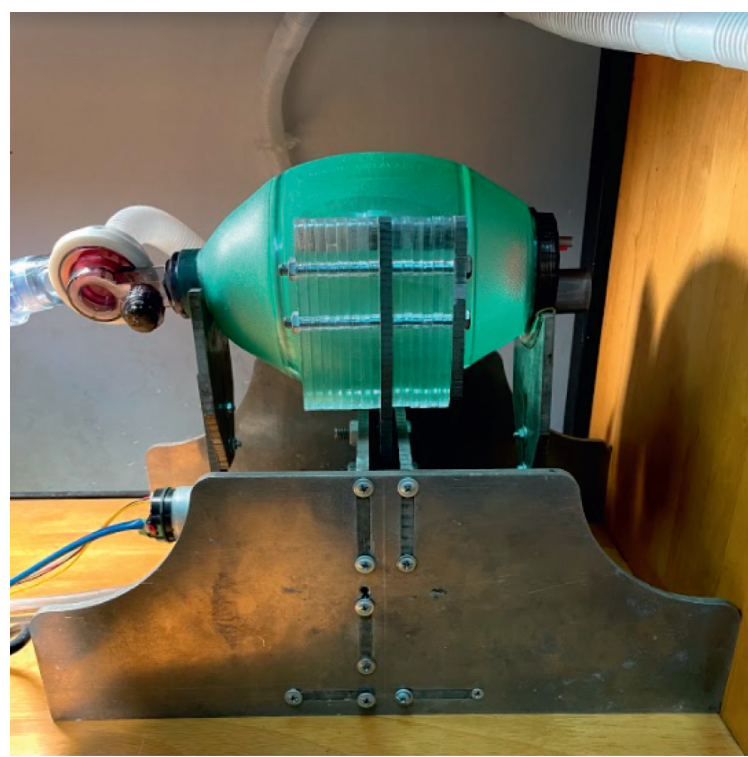

(a)

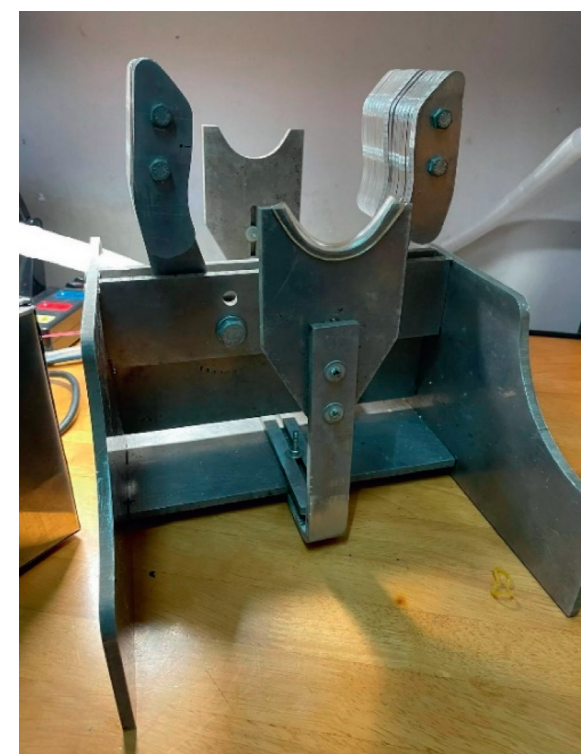

(b)

FiguRE 13: Experimental platform of the noninvasive mechanical ventilator, (a) overall experiment, and (b) hardware platform of mechanical ventilator.

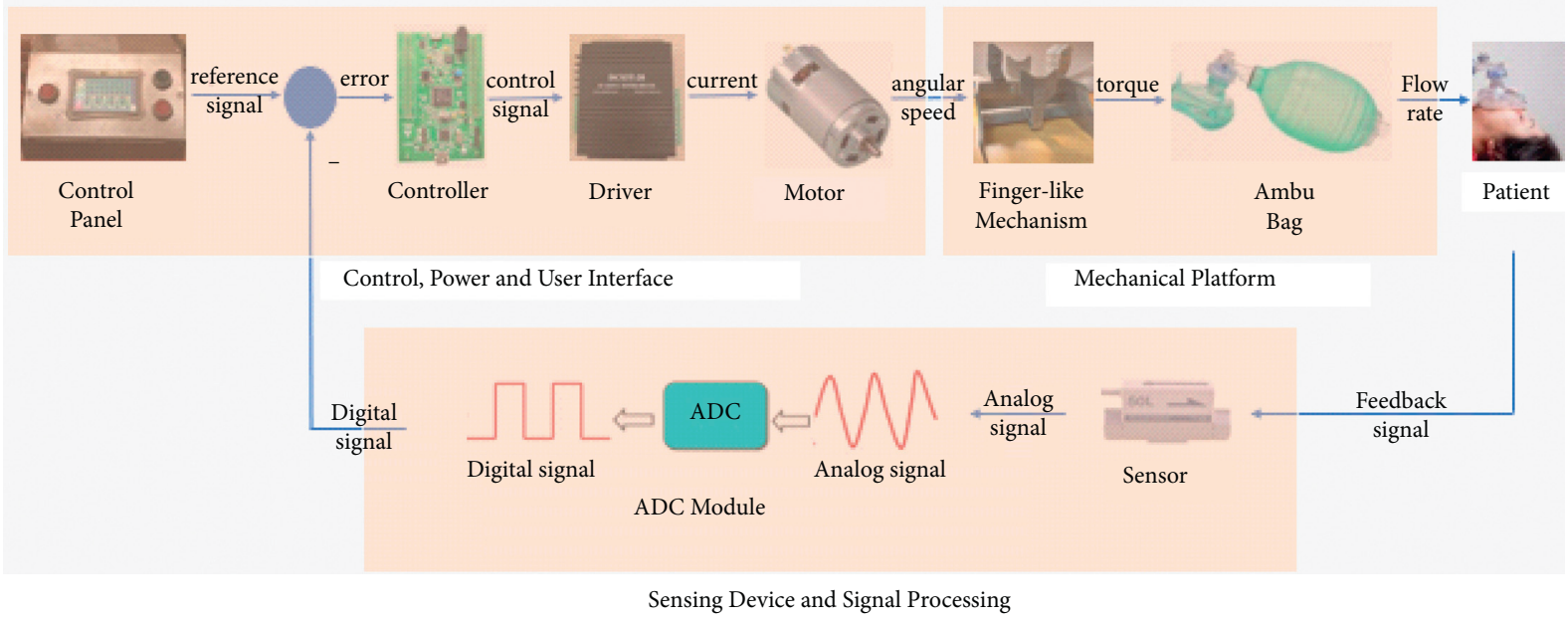

Figure 14: Block diagram of overall system in experiments.

power circuit. The positioning data from DCM50-775 servo motor is feedback to controller in order to measure the angular rotation of finger-like mechanism. In this work, the Ambu Bag determines the transfer function which comprises the driving torque of finger-like mechanism as input and the flow rate supply as output, by system identification toolbox in Matlab. Henceforth, the input flow rate could be estimated and delivered to patient. The measurement of flow rate output is returned to main CPU via Keyence FD-A sensor. From this scheme, the ventilating system is completely manipulated by our proposed controller. The experimental results in the first case are demonstrated in Figures 15, 16, and 17. Our control scheme is to provide the sufficient flow rate of air in respect to patient's need. At the initial stage, the main microcontroller is programmed to manipulate the driving mechanism in order to track the desired reference signal. To meet the requirement, the finger-like mechanism allows frequent operation with sufficient torque. When reaching the target value, the actuator holds the Ambu Bag slightly and slowly so that the tracking error of flow rate tends to zero. The result of tracking performance between input and output is manifested as Figure 15 while the error of flow rate is specified in Figure 16. In the second case, the results measured from the practical hardware are illustrated in Figures 18, 19, and 20. Because of the rapid response, the mechanical actuator completes its trajectory during a short period while the driving torque is greater in order to supply the larger flow rate. The competitive 


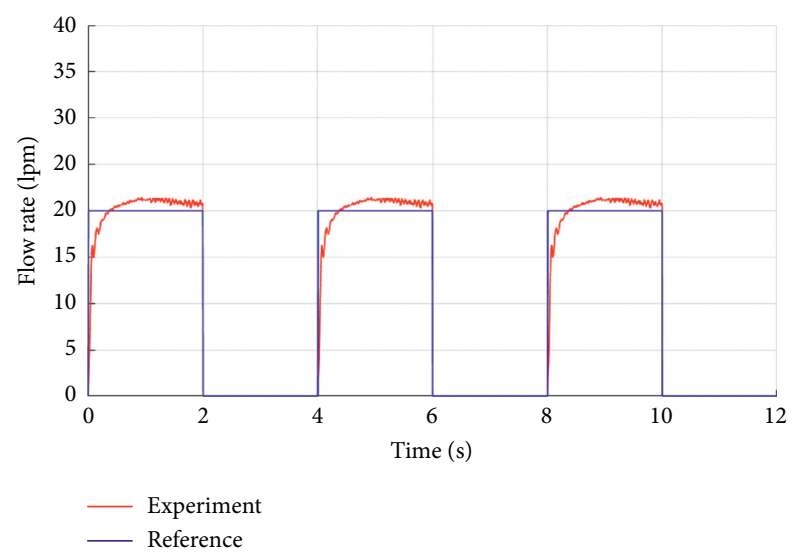

FIgURE 15: Experimental result in flow rate for normal breath, $\mathrm{VT}=700 \mathrm{ml}$, reference flow rate $=20 \mathrm{lpm}$ during a period of 4 seconds.

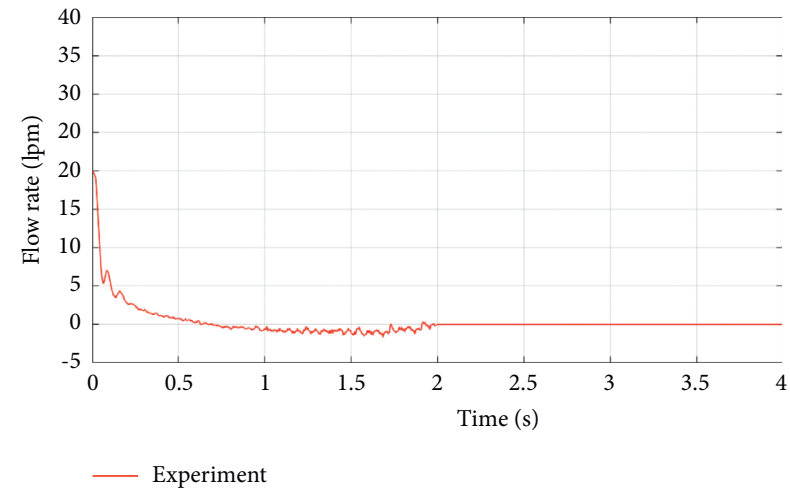

FIGURE 16: Experimental result in tracking error of flow rate for normal breath, $\mathrm{VT}=700 \mathrm{ml}$, reference flow rate $=20 \mathrm{lpm}$ during a period of 4 seconds.

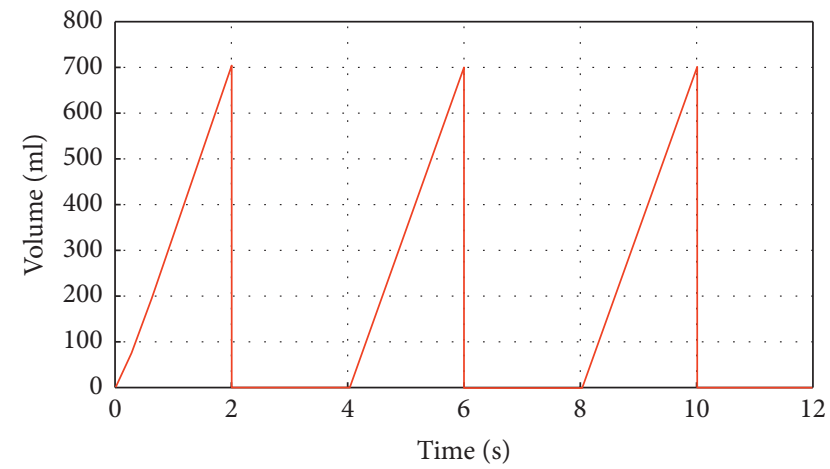

Experiment

Figure 17: Experimental result in volume for normal breath, $\mathrm{VT}=700 \mathrm{ml}$, reference flow rate $=20 \mathrm{lpm}$ during a period of 4 seconds.

performance between input and output of flow rate is shown as Figure 18 while the tracking error is shown as Figure 19. Although the greater amount of air in shorter duration is required, the control effort from proposed controller still adapts well. Furthermore, the system performance in urgent

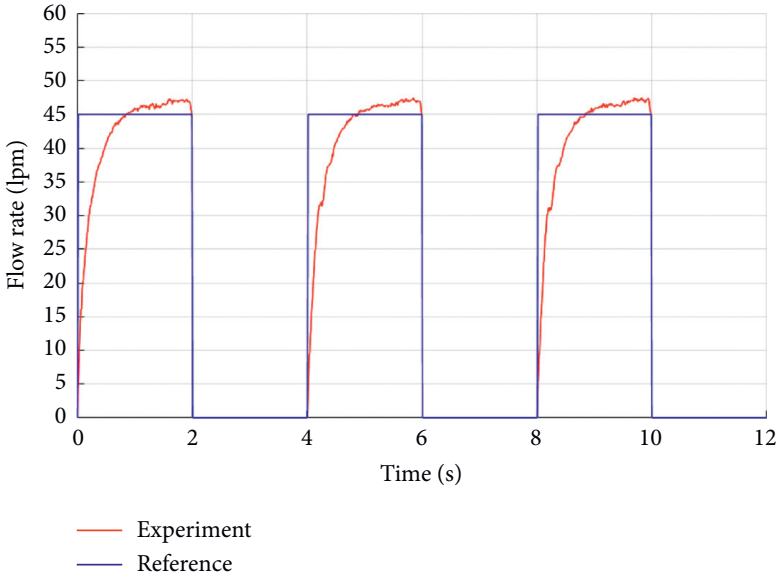

Figure 18: Experimental result in flow rate for urgent breath, $\mathrm{VT}=700 \mathrm{ml}$, reference flow rate $=45 \mathrm{lpm}$ during a period of 2.5 seconds.

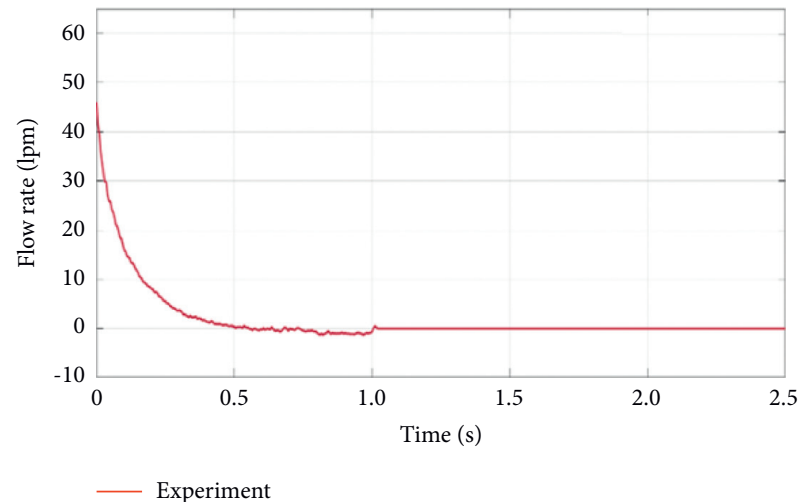

FIGURE 19: Experimental result in tracking error of flow rate for urgent breath, $\mathrm{VT}=700 \mathrm{ml}$, reference flow rate $=45 \mathrm{lpm}$ during a period of 2.5 seconds.

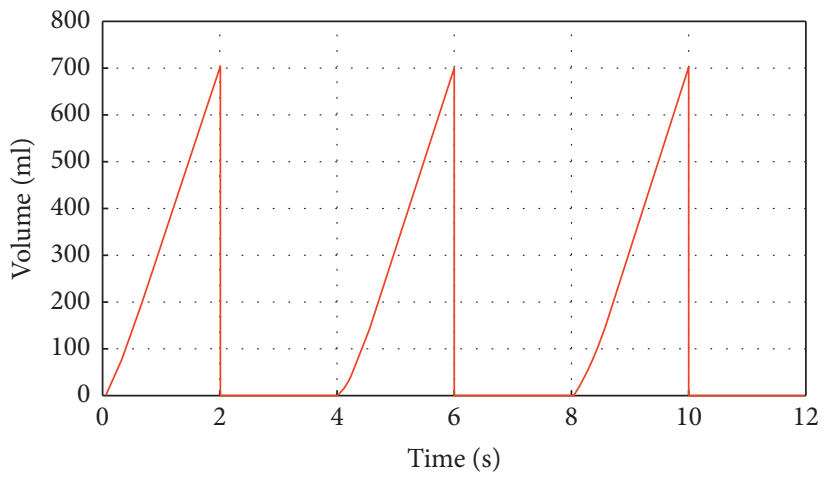

FIgURE 20: Experimental result in volume for urgent breath, $\mathrm{VT}=700 \mathrm{ml}$, reference flow rate $=45 \mathrm{lpm}$ during a period of 2.5 seconds.

case is reasonable, and there is no significant fluctuation in the tracking error of the flow rate.

To support the comparative performance, Table 1 visually presents the statistical data of the experiments. In 
TABLE 1: Tracking error in flow rate for both cases.

\begin{tabular}{lcccc}
\hline Type of breath & Max & Min & Average & RMS (root-mean-square) \\
\hline Normal breath & $23,2(\mathrm{lpm})$ & $0,12(\mathrm{lpm})$ & $1,811(\mathrm{lpm})$ & $1.542(\mathrm{lpm})$ \\
Urgent breath & $47,6(\mathrm{lpm})$ & $0,08(\mathrm{lpm})$ & $1,913(\mathrm{lpm})$ & $1.767(\mathrm{lpm})$ \\
\hline
\end{tabular}

general, the upper value of the urgent case is higher than the normal case, since the desired flow rate is at maximum at the initial stage. Later, the control scheme senses the difference between the reference value and feedback value and manipulates the driving mechanism in order to track this. When the target rate is almost reached, the mechanical actuator is tuned to deliver the airflow. The average value of the flow rate of normal breath is smaller than urgent breath owing to the shorter period, while the minimum flow rate in the normal case is larger. It can be clearly seen that the controller makes a great deal of effort to achieve the output results, although it suffers the limitation of the timing cycle. Additionally, there is no significant variance in the RMS (root-mean-square) value between cases. Although this study points out several beneficial results, it still needs to discuss the existing challenges. The closed-loop ventilation mode could offer better tracking performance; nonetheless, if both respiratory rate and tidal volume are automatically adjusted, then greater effectiveness in treatment might be gained. Above and beyond, the oxygen source mainly comes from Ambu Bag which characterizes the nonlinear properties. To stabilize and easily predict the airway, the deviceinduced solution such oxygenator machine should be considered.

\section{Conclusion}

In response to the global pandemic, an innovative design for a mechanical ventilator with a systematic analysis and computational theory was presented. With medical knowledge as well as a mechanical investigation, a novel idea to integrate the lung model with physiological characteristics has been embedded into the ventilator platform. As a result, the control scheme was successfully developed to regulate volume together with pressure. The proper framework for mechanical components was suggested with the computational criteria in detail. In this paper, the biological performance and driving mechanism were estimated by several mathematical expressions so that the desired flow rate in each period could be achieved. To verify the correctness and effectiveness of our approach, the modeling simulation and experimental trial were implemented in two cases: $20 \mathrm{lpm}$ for 4 seconds and $45 \mathrm{lpm}$ for 2.5 seconds as reference flow rates for a normal breath and urgent breath, respectively. The proposed ventilator achieved superior tracking error in airflow for both test cases: 1.542 and 1.767, respectively. From the results of this study, the usefulness and feasibility of our approach have been proven, indicating an excellent solution for emergency cases. This technology is available for large scales of users such as clinicians, educators, business vendors, or communities.

Future work is urgent. Although the hardware mechanism has been evaluated by mathematics, there still exist some limitations due to the uncertainties and nonlinear characteristics. Therefore, the advanced control schemes, which might be the theory of the neural network or fuzzy logic, should compensate the unexpected factors and lead to greater driving command. Furthermore, one of the problems in the current design is the feedback signal from the patient. More parameters, for instance, heart rate or saturation of peripheral oxygen, need to be collected from various sensing devices. Later, these constraints could be embedded into the control loop in order to determine the present status of patients.

\section{Nomenclature}

$P_{\text {muscle }}: \quad$ Muscle pressure or alveolar pressure

$P_{\text {ventilator }}$ Ventilator outlet pressure or pressure

support ventilation

$P_{\text {trans }}: \quad$ Transrespiratory system pressure

$P_{\text {opening }}: \quad$ Pressure at the airway opening

$P_{\text {body }}: \quad$ Pressure at the body surface

$P_{\text {transpulmonary }}$ : Transpulmonary Pressure

$P_{\text {pleural }}$ : Pleural pressure

$E: \quad$ Elastance

$E_{\text {load }}$ Elastic load

$V_{\text {ins }}$ : Inspiratory lung volume

$V_{\text {muscle }}$ : The volume generated by the patient's muscle pressure

$V_{\text {target }}$ : The tidal volume target set by the operator

$T_{i}: \quad$ Inspiratory sampling time

$R: \quad$ Resistance

$R_{\text {load }}: \quad$ Resistive load

Fl: $\quad$ Flow

C: $\quad$ Compliance or lung compliance

PEEP: $\quad$ Positive end-expiratory pressure.

\section{Data Availability}

No data were used to support this study.

\section{Conflicts of Interest}

The authors declare no conflicts of interest.

\section{Acknowledgments}

This research was funded by Japan International Cooperation Agency Project for Asean University Network/Southeast Asia Engineering Education Development Network (JICA Project for AUN/SEED-Net) in the framework of Special Program for Research against COVID-19 Japanese Fiscal Year 2020-2021 (SPRAC) with the support of time and facilities from Ho Chi Minh City University of Technology (HCMUT), VNU-HCM, for this study. 


\section{References}

[1] L. Brochard, A. Slutsky, and A. Pesenti, "Mechanical ventilation to minimize progression of lung injury in acute respiratory failure," American Journal of Respiratory and Critical Care Medicine, vol. 195, no. 4, pp. 438-442, 2017.

[2] R. L. Chatburn, M. El-Khatib, and E. Mireles-Cabodevila, "A taxonomy for mechanical ventilation: 10 fundamental maxims," Respiratory Care, vol. 59, no. 11, pp. 1747-1763, 2014.

[3] N. Rittayamai, C. M. Katsios, F. Beloncle, J. O. Friedrich, J. Mancebo, and L. Brochard, "Pressure-controlled vs volumecontrolled ventilation in acute respiratory failure," Chest, vol. 148 , no. 2 , pp. $340-355,2015$.

[4] I. I. Ramirez, D. H. Arellano, R. S. Adasme et al., "Ability of ICU health-care professionals to identify patient-ventilator asynchrony using waveform analysis," Respiratory Care, vol. 62, no. 2, pp. 144-149, 2017.

[5] Y. Shi, B. Zhang, M. Cai, and W. Xu, "Coupling effect of double lungs on a VCV ventilator with automatic secretion clearance function," IEEE/ACM Transactions on Computational Biology and Bioinformatics, vol. 16, no. 4, pp. 1280-1287, 2017.

[6] C. E. Mazzucco, A. Marchi, V. Bari et al., "Mechanical ventilatory modes and cardioventilatory phase synchronization in acute respiratory failure patients," Physiological Measurement, vol. 38, no. 5, pp. 895-911, 2017.

[7] R. L. Dellaca', C. Veneroni, and R. Farre', "Trends in mechanical ventilation: are we ventilating our patients in the best possible way?" Breathe, vol. 13, no. 2, pp. 84-98, 2017.

[8] Z. Zhang, W. J. Gu, K. Chen, and H. Ni, "Mechanical ventilation during extracorporeal membrane oxygenation in patients with acute severe respiratory failure," Canadian Respiratory Journal, vol. 2017, Article ID 1783857, 2017.

[9] D. Sanchez-Morillo, O. Olaby, M. A. Fernandez-Granero, and A. Leon-Jimenez, "Physiological closed-loop control in intelligent oxygen therapy: a review," Computer Methods and Programs in Biomedicine, vol. 146, pp. 101-108, 2017.

[10] J. C. Ferreira, F. Diniz-Silva, H. T. Moriya, A. M. Alencar, M. B. P. Amato, and C. R. R. Carvalho, "Neurally Adjusted Ventilatory Assist (NAVA) or Pressure Support Ventilation (PSV) during spontaneous breathing trials in critically ill patients: a crossover trial," BMC Pulmonary Medicine, vol. 17, no. 1, pp. 139-9, 2017.

[11] L. Liu, X. Xu, Q. Sun et al., "Neurally adjusted ventilatory assist versus pressure support ventilation in difficult weaning," Anesthesiology, vol. 132, no. 6, pp. 1482-1493, 2020.

[12] J. Botha, C. Green, I. Carney, K. Haji, S. Gupta, and R. Tiruvoipati, "Proportional assist ventilation versus pressure support ventilation in weaning ventilation: a pilot randomised controlled trial," Critical care and resuscitation: Journal of the Australasian Academy of Critical Care Medicine, vol. 20, no. 1, pp. 33-40, 2018.

[13] R. Saunders and D. Geogopoulos, "Evaluating the cost-effectiveness of proportional-assist ventilation plus vs. pressure support ventilation in the intensive care unit in two countries," Frontiers in Public Health, vol. 6, Article ID 168, 2018.

[14] A. H. Jonkman, M. Rauseo, G. Carteaux et al., "Proportional modes of ventilation: technology to assist physiology," Intensive Care Medicine, vol. 46, pp. 2301-2313, 2020.

[15] T. P. Velavan and C. G. Meyer, "The COVID-19 epidemic," Tropical Medicine and International Health, vol. 25, no. 3, pp. 278-280, 2020.

[16] C. Guerin, M. Cour, N. Stevic et al., Sharing Ventilators in the Covid-19 Pandemics. A Bench Study, medRxiv, NY, USA, 2020.
[17] O. Garmendia, M. A. Rodríguez-Lazaro, J. Otero et al., "Lowcost, easy-to-build noninvasive pressure support ventilator for under-resourced regions: open source hardware description, performance and feasibility testing," European Respiratory Journal, vol. 55, no. 6, 2020.

[18] J. Zuckerberg, M. Shaik, K. Widmeier, T. Kilbaugh, and T. D. Nelin, "A lung for all: novel mechanical ventilator for emergency and low-resource settings," Life Sciences, vol. 257, Article ID 118113, 2020.

[19] S. Mora, F. Duarte, and C. Ratti, Can Open Source Hardware Mechanical Ventilator (OSH-MVs) Initiatives Help Cope with the COVID-19 Health Crisis? Taxonomy and State of the Art, Elsevier, Amsterdam, The Netherlands, Article ID e00150, 2020.

[20] J.-M. Arnal, M. Wysocki, D. Novotni et al., "Safety and efficacy of a fully closed-loop control ventilation (IntelliVentASV) in sedated ICU patients with acute respiratory failure: a prospective randomized crossover study," Intensive Care Medicine, vol. 38, no. 5, pp. 781-787, 2012.

[21] J. M. Arnal, A. Garnero, D. Novonti et al., "Feasibility study on full closed-loop control ventilation (IntelliVent-ASV ${ }^{\mathrm{TM}}$ ) in ICU patients with acute respiratory failure: a prospective observational comparative study," Critical Care, vol. 17, no. 5, pp. 1-10, 2013.

[22] J.-M. Arnal, M. Saoli, and A. Garnero, "Airway and transpulmonary driving pressures and mechanical powers selected by INTELLiVENT-ASV in passive, mechanically ventilated ICU patients," Heart \& Lung, vol. 49, no. 4, pp. 427-434, 2020.

[23] L. Piquilloud, L. Vignaux, E. Bialais et al., "Neurally adjusted ventilatory assist improves patient-ventilator interaction," Intensive Care Medicine, vol. 37, no. 2, pp. 263-271, 2011.

[24] R. M. Kacmarek, J. Villar, D. Parrilla et al., "Neurally adjusted ventilatory assist in acute respiratory failure: a randomized controlled trial," Intensive Care Medicine, vol. 46, no. 12, pp. 2327-2337, 2020.

[25] C. Karagiannidis, S. Strassmann, S. Schwarz et al., "Control of respiratory drive by extracorporeal $\mathrm{CO} 2$ removal in acute exacerbation of COPD breathing on non-invasive NAVA," Critical Care (London, England), vol. 23, no. 1, pp. 135-139, 2019.

[26] B. K. Tirupakuzhi Vijayaraghavan, S. Hamed, A. Jain et al., "Evidence supporting clinical use of proportional assist ventilation: a systematic review and meta-analysis of clinical trials," Journal of Intensive Care Medicine, vol. 35, no. 7, pp. 627-635, 2020.

[27] K. A. Hunt, T. Dassios, and A. Greenough, "Proportional assist ventilation (PAV) versus neurally adjusted ventilator assist (NAVA): effect on oxygenation in infants with evolving or established bronchopulmonary dysplasia," European Journal of Pediatrics, vol. 179, no. 6, pp. 901-908, 2020.

[28] Y. Chen, Y. Yuan, C. Cai, F. Li, and X. Zhou, "Effects of assist parameter on the performance of proportional assist ventilation in a lung model of chronic obstructive pulmonary disease," Respiratory Medicine and Research, vol. 78, Article ID 100766, 2020.

[29] L. Acho, A. N. Vargas, and G. Pujol-Vázquez, "September). Low-cost, open-source mechanical ventilator with pulmonary monitoring for COVID-19 patients," Actuators, Multidisciplinary Digital Publishing Institute, vol. 9, no. 3, p. 84, 2020.

[30] F. S. Sayin and H. Erdal, "Design, modelling, prototyping and closed loop control of a mechanical ventilator for newborn babies," in Proceedings of the 2018 6th International Conference on Control Engineering \& Information Technology (CEIT), pp. 1-5, IEEE, Istanbul, Turkey, October 2018. 
[31] R. Amirnovin, S. Aghamohammadi, C. Riley, M. S. Woo, and S. Del Castillo, "Analysis of a pediatric home mechanical ventilator population," Respiratory Care, vol. 63, no. 5, pp. 558-564, 2018.

[32] A. Abba, C. Accorsi, P. Agnes et al., "The novel mechanical ventilator milano for the COVID-19 pandemic," Physics of Fluids, vol. 33, no. 3, 2021.

[33] A. Darwood, J. McCanny, R. Kwasnicki, B. Martin, and P. Jones, "The design and evaluation of a novel low-cost portable ventilator," Anaesthesia, vol. 74, no. 11, pp. 1406-1415, 2019.

[34] A. H. Kwon, A. H. Slocum, A. H. Slocum, D. Varelmann, and C. G. S. Nabzdyk, "Rapidly scalable mechanical ventilator for the COVID-19 pandemic," Intensive Care Medicine, vol. 46, no. 8, pp. 1642-1644, 2020.

[35] M. R. Islam, M. Ahmad, M. S. Hossain, M. M. Islam, and S. F. U. Ahmed, "Designing an electro-mechanical ventilator based on double cam integration mechanism," in Proceedings of the 2019 1st International Conference on Advances in Science, Engineering and Robotics Technology (ICASERT), pp. 1-6, IEEE, Dhaka, Bangladesh, May 2019.

[36] E. Castro-Camus, J. Ornik, C. Mach et al., "Simple ventilators for emergency use based on Bag-Valve pressing systems: lessons learned and future steps," Applied Sciences, vol. 10, no. 20, Article ID 7229, 2020.

[37] A. Petsiuk, N. G. Tanikella, S. Dertinger, A. Pringle, S. Oberloier, and J. M. Pearce, "Partially RepRapable automated open source bag valve mask-based ventilator," HardwareX, vol. 8, Article ID e00131, 2020.

[38] M. I. T. E-Vent, "MIT emergency ventilator project," https:// e-vent.mit.edu/.

[39] AndalucíaRespira: https://www.andaluciarespira.com/en/and alucia-respira-en/.

[40] A. F. de Castro and L. A. Borges Tôrres, "Iterative learning control applied to a recently proposed mechanical ventilator topology," IFAC-PapersOnLine, vol. 52, no. 1, pp. 154-159, 2019.

[41] M. Cressoni, M. Gotti, C. Chiurazzi et al., "Mechanical power and development of ventilator-induced lung injury," Anesthesiology, vol. 124, no. 5, pp. 1100-1108, 2016.

[42] N. S. Khalil, W. Y. Mohamed, and M. A. M. Sharkawy, "Patients' weaning from mechanical ventilation: complete versus incomplete ventilator bundle implementation," International journal of Africa nursing Sciences, vol. 8, pp. 28-32, 2018.

[43] A. Kaesler, M. Rosen, P. C. Schlanstein et al., "How computational modeling can help to predict gas Transfer in artificial lungs early in the design process," ASAIO Journal, vol. 66, no. 6, pp. 683-690, 2020.

[44] J. A. Svoboda and R. C. Dorf, Introduction to Electric Circuits, John Wiley \& Sons, NY, USA, 2013.

[45] World Health Organization, Technical Specifications for Invasive and Non-invasive Ventilators for COVID-19: Interim Guidance, 15 April 2020, World Health Organization, 2020, https://apps.who.int/iris/handle/10665/331792.Licence:CCBYNC-SA3.0IGO. 